\title{
The correspondence problem in syntactic reconstruction*
}

\author{
George Walkden \\ University of Manchester
}

While considerable swathes of the phonology and morphology of protolanguages have been reconstructed using the comparative method, syntax has lagged behind. Jeffers (1976) and Lightfoot (2002a), among others, have questioned whether syntax can be reconstructed at all, claiming that a fundamental problem exists in applying the techniques of phonological reconstruction to syntax. Others, such as Harris \& Campbell (1995) and, following them, Barðdal \& Eythórsson (2012), have claimed that the problem does not arise in their frameworks. This paper critically examines the isomorphism between phonological and syntactic reconstruction, made possible by an 'item-based' view of syntactic variation as assumed within Minimalist theories of syntax as well as Construction Grammar and others. A case study dealing with the 'middle voice' suffix -sk in early North Germanic is presented in support of the approach. While the conclusion drawn is not as pessimistic as that of Lightfoot (2002a), it is argued that the 'correspondence problem' is real and that reconstruction of syntax is therefore necessarily more difficult, and speculative, than that of phonology.

Keywords: syntactic reconstruction, historical syntax, comparative method, cognacy, correspondence problem, regularity, directionality

* This work was funded by UK Arts \& Humanities Research Council grants AH/H139518/1 and AH/H026924/1 and presented in Cambridge, Manchester, Newcastle and Osaka. I am grateful to audiences at those events and to colleagues and coursemates at the University of Cambridge: Alastair Appleton, Theresa Biberauer, Elliott Lash, Christopher Lucas, Ian Roberts, Richard Waltereit, Sheila Watts and especially David Willis. I am also grateful to Joe Salmons, Matthew Juge and Diachronica's anonymous reviewers for their comments, which have led to substantial revisions, hopefully in the direction of greater clarity. I am responsible for all remaining errors. 


\section{Introduction}

The question of whether it is possible to reconstruct the syntax of proto-languages has long occupied both Indo-Europeanists (e.g. Brugmann 1904:624, Clackson 2007: 157-186) and theorists of syntactic change (e.g. Lightfoot 1979a: 154-166, 1979b, 2002a, 2006, Harris \& Campbell 1995:344-376, Roberts 2007:357-368). Though a volume on the subject (Ferraresi \& Goldbach 2008) was recently published, it revealed little consensus on principles or general methodology for syntactic reconstruction. Lightfoot (2002b:625) states the challenge to advocates of syntactic reconstruction as follows: "If somebody thinks that they can reconstruct grammars more successfully and in more widespread fashion, let them tell us their methods and show us their results. Then we'll eat the pudding."

The present contribution sketches a method for meeting Lightfoot's challenge, illustrated by a case study from Germanic. The paper aims to demonstrate, through consideration of the analogy between phonological and syntactic variation, that Lightfoot's 'correspondence problem' - the claim that correspondence sets cannot be constructed for syntax exactly as they can be for phonology - is real. It is argued that plausible hypotheses about the prehistory of grammars can nevertheless be stated, albeit with less certainty than in phonological-lexical reconstruction.

The paper is structured as follows: $\$ 2$ discusses ideas about syntactic reconstruction, focusing particularly on the correspondence problem. In $\$ 3$ I make concrete suggestions about how to work around this problem, based on a partial isomorphism between phonological and syntactic variation. $\$ 4$ puts this method into practice, considering the 'middle voice' ending -sk in early North Germanic. It is argued that correspondences can be identified here and that syntactic reconstruction is therefore possible even in cases of non-identity. $\$ 5$ recapitulates and discusses language contact as a confounding factor. $\$ 6$ concludes that, though the reconstruction of syntax is necessarily more difficult and speculative than that of phonology, plausible reconstructions can be achieved.

\section{Methods for reconstructing syntax: An overview}

Armed with the family tree model of Schleicher (1853) and Osthoff \& Brugmann's (1878) Regularity Hypothesis, comparative philologists in the 19th and early 20th centuries were able to make massive strides forward in hypothesising genetic relatedness and in postulating proto-forms for the lexicon, phonology and morphology of unattested stages in family trees. Many of the achievements of scholars of this period are still widely accepted today. For example, the 'best fit' Indo-European 
family trees generated by Ringe, Warnow \& Taylor (2003) using computational methods are extremely similar to the classical tree presented in Schleicher (1853), still used as a yardstick against which to measure newer attempts at constructing phylogenies. ${ }^{1}$

However, as has been noted by many authors (e.g. Brugmann 1904:viii; Watkins 1964: 1035; Clackson 2007: 157), comparative linguistics has not always accorded syntax a central place. For example, Beekes' 1995 introduction to IndoEuropean philology omits syntax entirely. This section outlines some attempts to reconstruct syntax and the criticisms. In $\$ 2.4$ I discuss more recent attempts based on notions of patterns and constructions (Harris \& Campbell 1995 and Barðdal \& Eythórsson 2012), arguing that, although promising, these approaches do not in fact escape the correspondence problem.

\subsection{Early attempts}

Delbrück, a pioneer of comparative syntax, saw himself as using the same method employed in lexical and phonological reconstruction (1893:1), but he drew attention to important procedural differences: in syntax, he argues, it is not appropriate to reconstruct proto-forms as in phonology, and his work should thus be seen as "a presentation, laid out in converging lines, of the oldest stages of the Indo-European languages referred to" (1900: vi; my translation) rather than as a reconstruction.

Delbrück's most famous claim is that Proto-Indo-European was basically verb-final (1900: 83), which he bases largely on evidence that in Sanskrit the verb is habitually final but occurs in initial position for reasons of emphasis (1900:81). He suggests that the formerly 'occasional' pattern has become 'habitual' in the verbinitial Celtic languages, but he provides no explanation for why this should be the case and not the opposite; the archaic attestation of the oldest Sanskrit is assumed to speak for itself.

Work by Calvert Watkins $(1964,1976)$ can be seen as a continuation of this tradition, based on the hypothesis that historical relatedness often gives rise to recurrent similarities of syntactic patterning. Watkins (1976) gives four examples of sentences about athletic contests, from Hittite, Vedic and early Greek, and

1. More recent phylogenetic work, e.g. Dunn et al. (2008) and Longobardi \& Guardiano (2009), has in fact attempted to use syntactic properties as the basis for establishing historical relatedness on the grounds that structural features of a language are likely to be more diachronically stable (cf. Nichols 2003, Keenan 2003) and hence allow for construction of phylogenies at a potentially greater time depth. The emergence of this sort of work adds urgency to the debate on syntactic reconstruction, since both for phylogenetic and reconstructive purposes it is necessary to know how to proceed when the languages under consideration do not exhibit identity; see $\$ 2$. The two enterprises should be able to inform one another, as they are two sides of the same coin. 
concludes that "we have little choice but to assume the way you said that sort of thing in Indo-European could not have been very different" (1976:315). In response, Lightfoot accepts the claim that genetic relatedness may give rise to striking similarities, but argues that problems arise when the patterns attested in the daughter languages are not alike, and that therefore one can only reconstruct syntactic patterns where the daughter languages show identity (2002a: 120). It is difficult to see how Watkins's (or Delbrück's) approach could deal with differences between the languages under comparison, since they do not provide a method for doing so.

'Traditional' syntactic reconstruction as practised by Delbrück and Watkins, then, has led to plausible results only where strong similarity or identity can be found. This is a crucial departure from the phonological comparative method, in which systematic correspondences, not structural similarity, are diagnostic for cognacy. This discrepancy may explain why the reconstruction of syntax lagged behind that of phonology in traditional scholarship: the methods used do not provide a firm basis for far-reaching inferences about the syntactic structure of protolanguages.

\subsection{Typological attempts}

In contrast to the above, the typological tradition of syntactic reconstruction as practised in the 1970s targeted exactly such far-reaching generalizations. Lehmann (1974) attempts to use a strong theory of typological consistency inspired by the work of Greenberg (1963) in reconstruction. Many of his conclusions are in line with Delbrück's, e.g. that Proto-Indo-European (PIE) was basically verb-final (1974:31).

The OV structure of Proto-Indo-European is simultaneously the book's main conclusion and its main assumption. For instance, examples of standard-pivotcomparative and of comparative-pivot-standard orders from Sanskrit are given (1974:31); Lehmann interprets the former as unmarked, as it correlates with OV in his theory, and the latter as innovative; he then claims that this is evidence for the OV structure of PIE, since OV and standard-pivot-comparative are 'harmonic' under his theory.

Lehmann also makes some assertions about typological correlations that are demonstrably false. For instance, he asserts that sentential connectives are characteristic of VSO languages (1974:215). He is therefore forced to explain the ubiquity of the connectives $n u, s ̌ u$ and $t a$ in largely OV Hittite through contact with Akkadian and sá and tád in largely OV Vedic through other outside influence (1974:215), making no mention of the extremely common connective jah in largely OV Gothic. 
Friedrich (1975) and Miller (1975) also employed essentially the same typological method and reached different results based on differing interpretations of the data: Friedrich suggests that Proto-Indo-European may have been SVO, and Miller that it may have been VSO. The typological method of syntactic reconstruction, which has been extensively criticized elsewhere (e.g. Watkins 1976, Smith 1981, McMahon 1994, Lightfoot 2002a), cannot therefore be relied upon.

\subsection{Potential problems for syntactic reconstruction: Lightfoot (2002a)}

Harris \& Campbell (1995:344) recognize two steps in the phonological comparative method: the establishment of correspondences and the reconstruction of proto-forms. Lightfoot (2002a, 2002b) has argued that neither step is possible in syntax, a conclusion which he maintains in more recent work (Lightfoot 2006: 167-178). I review his objections and discuss them critically, including an exegesis of the oft-misunderstood correspondence problem.

Lightfoot's first objection will be termed the 'directionality problem' and is related to the second step of reconstruction. In phonological reconstruction, statements about the predictable direction of sound change help us to reconstruct proto-sounds: for instance, $\mathrm{b}>\mathrm{p} / \mathrm{V} \_\mathrm{V}$ is a highly unlikely change, whereas $\mathrm{p}$ $>$ b / V__ V is natural and often found (cf. Harris \& Campbell 1995:361). On the basis of his view that a theory of change should reduce to a theory of grammar and acquisition, Lightfoot (2002a) denies the existence of (uni)directionality: "we have no well-founded basis for claiming that languages or grammars change in one direction but not in another" (2002a: 126). In response, Campbell \& Harris (2002:612) argue that, although unidirectionality is rightly controversial, tendencies of directionality can be established and that appealing to directionality is not only a valid criterion in the application of the comparative method but is fundamental to it. Even those who have criticisms of grammaticalization theory or of the strong conception of unidirectionality (e.g. Juge 2002) are prepared to admit that instances of change from less grammatical to more grammatical are vastly more common than changes in the opposite direction (Campbell 2001:133). Though denying that directionality of syntactic change is absolute and that grammaticalization can be explanatory, Lightfoot (2006:177) acknowledges that tendencies of directionality may exist and that "grammaticalization is a real phenomenon". Since reconstructions are a matter of qualitative probability (Dressler 1971:6), rather than of mechanical certainty, a minority of counterexamples to the prevailing tendency should not concern us much when carrying out reconstruction.

Directionality cannot be established for all types of sound change, of course; the changes $/ \mathrm{a} />/ \mathrm{o} /$ and $/ \mathrm{o} />/ \mathrm{a} /$, for instance, seem to be equally possible (cf. Barðdal 2013), and lenition and fortition are mirror-image processes that appear 
equally natural in some contexts (Kiparsky 1988). It follows that it will not always be possible for reconstruction to be guided by directionality considerations, either in phonology or in syntax. Furthermore, syntactic change is not constrained by the physical demands of the articulatory system in the same way as sound change. However, two further criteria other than directionality can also be used to guide our postulation of syntactic proto-forms, both of which have analogues in phonological reconstruction (Lass 1993). Synchronic typology is one: if a typological pattern appears to hold in all attested languages, for example the absence of clausefinal complementizers in VO languages (Dryer 1992: 102, Hawkins 1990:225), we should assume that it holds of all possible languages, so we should be wary of positing a system that violates such apparent universals (see also von Mengden 2008). Of course, the usefulness of typological generalizations is dependent on their accuracy; see Wichmann (2008) for discussion of potential pitfalls, as well as $\$ 2.2$ above for criticism of Lehmann’s (1974) approach. The typological criterion does not replace traditional reconstructive techniques; rather, it is a heuristic to be used alongside them, and with care.

The third guiding criterion is economy, or Ockham's razor: all else being equal, we should adopt the hypothesis which posits the minimal number of changes to derive the attested data (Hale 2007:240). This principle is implicit in all phonological reconstruction: we do not posit an intermediate stage in a phonological change unless considerations of directionality make it unavoidable. Hale argues that it is dangerous to apply this criterion, since the change under investigation may itself be evidence for subgrouping: if three related languages show one variant and another related language shows another, and if the variant shared by the three languages is likely to be innovative, it would be sufficient grounds for subgrouping the three languages together as against the fourth (2007:240-242). Hale's point is well taken as a cautionary note when applying the criterion of economy; in cases where subgroupings have already been safely established, however, such as the West Germanic languages as opposed to Gothic, we can make confident inferences on the basis of such a criterion.

The 'directionality problem' and the postulation of proto-forms once correspondences have been established, then, are no more problematic in syntax than they are in phonology. The problem with the first step, which I will term the 'correspondence problem, turns out to be much more significant. Lightfoot phrases it as follows (2002a: 119):

It is hard to know what a corresponding form could be in syntax, hard to know how one could define a sentence of French which corresponds to some sentence of English, and therefore hard to see how the comparative method could have anything to work with. 
Lightfoot is neither the first nor the only person to raise the issue of what can be compared in syntax (see Jeffers 1976, Watkins 1976:312, Winter 1984:622-623), although the issue is not always clearly stated. The problem lies in the application of the comparative method as applied in phonology to syntax, and I here attempt to make this application explicit.

Although difficult to define intensionally as a method (cf. Walkden 2009 for discussion), it is uncontroversial that the comparative method in phonologicallexical reconstruction involves hypothesizing correspondence sets in which both the lexical item and the sounds that constitute its phonological form are cognate, in the traditional sense of diachronic identity between those items and a single item in the proto-language through transmission across generations. ${ }^{2}$ I will state this crucial assumption as in (1):

(1) 'Double Cognacy Condition': In order to form a correspondence set, the contexts in which postulated cognate sounds occur must themselves be cognate.

In English pipe and German Pfeife, for example, we know that the initial /p/ and $/ \mathrm{pf} /$ are cognate because many other instances of /p/ and /pf/ corresponding in initial position are found (e.g. pepper $\sim$ Pfeffer). The lexical items themselves are also cognate, as each of their component sounds is part of a systematic correspondence in this way, and so a proto-lexeme could be reconstructed. But pipe and Pfeffer, for instance, would not qualify as part of a correspondence set in the traditional sense, since although initial /p/ and /pf/ can be argued to be cognate the other sounds that make up the item do not correspond.

Barðdal \& Eythórsson (2012) attempt to deny the logic of transmission by claiming that both the grammar and the vocabulary (and presumably the sounds) are not inherited directly but rather acquired indirectly on the basis of abstraction from the input. Though true, this line of reasoning misses the point of Lightfoot's argument. While it is clear that lexical items are not passed down through racial memory, they are nevertheless acquired extremely successfully by each generation; it is exactly this that secures the continued intelligibility of a language across generations. As Campbell \& Harris (2002: fn4) put it, "it is those aspects of language that can be stored in memory that are also potentially reconstructible": for them, these include patterns (understood in the sense of Jackendoff 1994), but not sentences. Crucially for Lightfoot's point, it is uncontroversial that lexical items

2. Although the term 'cognate' is usually applied only to words (cf. the definition in Trask 1996: 78), I use the term to apply to sounds in the clear sense mentioned by Harris \& Campbell: "sounds which are related to each other ... by virtue of descent from a common ancestral pronunciation" (1995: 345; also Harrison 2003: 221). 
are stored in some form in the mental lexicon in a way that sentences are not. To say that lexical items are transmitted, then, while obscuring some details of the process, is not technically false, but to claim it of sentences in general would be false, as discussed in the following, and this is the intuition behind the Double Cognacy Condition in (1).

The notion of context is fundamental to phonological reconstruction. Correspondence sets can be constructed because we can observe that the sounds constituting the phonological form of a lexical item are themselves cognate. We can do this because we know that sounds develop regularly according to the phonological environment they find themselves in: ${ }^{3}$ this is the Neogrammarian regularity hypothesis (Osthoff \& Brugmann 1878: xiii). Only in this way can we see how sounds (as individual items) have developed systematically across lexical items. Without the regularity hypothesis, positing correspondences between items is merely guesswork: in fact, lack of regular correspondences between sounds in words hypothesized to be cognate usually leads one to reject the cognacy of the words on the basis that some other process, such as borrowing, must have intervened.

Barðdal \& Eythórsson (2012) deny the importance of regularity for reconstruction. However, this is based on a non-standard use of terminology, namely the conflation of sound laws with developmental pathways: "the whole concept of 'sound laws' is based on possible developmental paths" (2012:9); "developmental paths gave rise to the concept of sound laws" (2012:5). As a result, they proceed to talk about the exceptionlessness (or lack thereof) of developmental paths (2012:9). To clarify: in phonology, developmental paths, or statements of directionality, have to do with the possibility or probability of a given sound change occurring in a given environment. As mentioned earlier in this section, for instance, $\mathrm{b}>\mathrm{p} / \mathrm{V} \_$_ $\mathrm{V}$ is a highly unlikely change, whereas $\mathrm{p}>\mathrm{b} / \mathrm{V} \_\mathrm{V}$ is 'natural' and often found (Harris \& Campbell 1995:361). As Barðdal \& Eythórsson rightly state, the exceptionlessness of developmental pathways is completely unimportant for reconstruction; on the other hand, the exceptionlessness of sound laws, the regularity of sound change, is a key component, as above. Regularity has nothing to do with directionality per se, but without regularity the whole edifice collapses, since if sounds were able to develop differently in different words regardless of phonological context there would be no basis for stating that two words or morphemes

3. A circularity thus emerges: in the comparative method, the cognacy of morphs is demonstrated by the cognacy of the sounds within them, which itself is demonstrated by the cognacy of the morphs in which they occur. This circularity is acceptable, however, to the extent that alternative explanations (chance similarity or massive borrowing) are less plausible in accounting for the data. The account is justified by its internal coherence, which goes some way towards defending against the charge of circularity. 
were cognate and thus no basis for reconstructing either the phoneme inventory or the lexicon of the proto-language.

In phonological reconstruction, then, two types of unit can be said to correspond: sounds (phonemes) and words (lexical items). Correspondences are established on the basis of both, since the sounds that constitute the phonological forms of two words under comparison must be identifiable as having developed regularly, systematically, from a proto-form in order for the two words to be identified as cognate.

What would these two types of unit be in syntax? As for the lower level unit, corresponding to the sound/phoneme, I will defer the answer until $\$ 3$. The higher level unit, however, corresponding to the context in which the lower level unit occurs, is a problem. The only meaningful context that any syntactic element could occur in is the sentence. However, it is clear that sentences, in the vast majority of cases, cannot be cognate in the traditional sense. Harris \& Campbell (1995:344) nevertheless refer to cognate sentences "in an intuitively clear sense", although Campbell \& Harris (2002:606) add an important clarification: "cognate sentences cannot, of course, be descended from a shared sentence ... ; they are examples of shared patterns descended from a pattern in the proto-language". As Lightfoot (2002a: 123) and von Mengden (2008: 103) note, this use of the term is out of step with its general use in the phonological comparative method, since for two items to be cognate in the traditional comparative method there must be a diachronic identity between those items and a single item in the proto-language, in the sense of transmission across generations.

As $\$ 3$ should make clear, although the arguments of Lightfoot (2002a) and von Mengden (2008) with regard to the cognacy of sentences are sound, it does not follow that the notion of cognate has no role in syntactic reconstruction. Insofar as they have psychological validity, patterns (Harris 2008), constructions (Barðdal \& Eythórsson 2012) and functional lexical items all have the potential for cognacy, since they are all units that are hypothesized to be acquired and transmitted across generations.

Patterns, in and of themselves, do not provide a way out of this problem, however. In a pattern-based theory of grammar such as Construction Grammar, sentences are still formed through composition (combination) of patterns/constructions (e.g. Michaelis 2012:39-40). Although abstract schematic constructions in

4. There are many different incarnations of Construction Grammar, which cash out the notion of combination in different ways. Working within Fluid Construction Grammar, Steels and de Beule (2006) point out the similarity between the Minimalist operation Merge (Chomsky 1995) and unification operations in the Construction Grammar and HPSG traditions (cf. also Hurford 2011:358). 
such a framework may make a number of slots available to be filled, considerable freedom is possible in filling these slots, and must be, in order to account for the discrete infinity of sentences that are grammatical in any language. The phonological matrices of lexical items also involve combination, in this case combination of phonemes, but here the combination is crucially not free: the phonological matrices are made up of a fixed set of phonemes in a fixed order. Patterns and constructions in syntactic reconstruction, then, cannot be quite analogous to lexical items in lexical-phonological reconstruction: the patterns/constructions themselves may be cognate, but the sentences they generate are not.

If the context in which lower-level syntactic items occur must be the sentence, and if sentences are not transmitted across generations in the standard case, then a clear lack of parallel between syntactic and phonological reconstruction is observed, since the Double Cognacy Condition in (1) cannot be met. ${ }^{5}$ In other words, pace e.g. Watkins (1976:306), Fox (1995: 105), Harris \& Campbell (1995) and Barðdal \& Eythórsson (2012), the comparative method as employed in phonology cannot be unproblematically applied to syntax.

To recapitulate: What would a correspondence set look like in syntactic reconstruction? In phonological reconstruction, a correspondence set consists of words presumed to be cognate on the basis that the sounds within them can all be analysed as cognate. Pursuing the isomorphism, a correspondence set in syntactic reconstruction would consist of sentences presumed to be cognate on the basis that the lexical items or constructions 'within' them could all be analysed as cognate. But, as we have seen, sentences cannot normally be cognate, if we interpret cognacy to mean diachronic identity. And if sentences are not transmitted, it is not meaningful to say that sentences preserve the evidence of lexical/constructional change in the same way that words preserve the evidence of phonological change. We therefore arrive at a real dilemma, one that vindicates Lightfoot's criticism, and the isomorphism between phonological and syntactic reconstruction partially breaks down here.

5. As a reviewer notes, the Double Cognacy Condition is a new name for a very old idea. In stating it as in (1) my aim is to make explicit the criterion that Jeffers (1976:5) and Lightfoot (1979b:386-387) hold to be present in lexical-phonological reconstruction but absent in syntactic reconstruction, in order to diagnose the reasons for the differences in opinion between authors. The recognition that the Double Cognacy Condition does not hold of syntax may in fact be implicit in Harris \& Campbell's (1995:349) statement that "syntax has nothing quite like the duality of patterning [in the sense of Hockett (1960) - GW] ... in phonology". To the extent that Harris \& Campbell’s own safeguards on cognacy, as discussed in $\$ 2.4$, are of use, they help to compensate for the lack of the Double Cognacy Condition in syntactic reconstruction and are not its equivalent. 


\subsection{Pattern- and construction-based attempts}

Harris \& Campbell argue that it is not only possible but also appropriate to use traditional reconstructive methods to reconstruct syntax (1995:344), suggesting that correspondences can be established in syntax in much the same way as in phonology. In contrast to Campbell \& Mithun (1980:19-20), who assert that syntactic change has "no direct analogue" of the regularity of sound change (see also Campbell 1990 and Barðdal \& Eythórsson 2012), Harris \& Campbell argue that "syntactic change is indeed regular, in the sense that it is rule-governed, nonrandom" (1995:347). For Harris \& Campbell, change is established in syntactic patterns. The examples they cite are from Harris (1985:52-53), from the languages Mingrelian (2a) and Laz (2b):

(2) a. zaza oškviduans nodar-s Zaza.NOM he.drown.him Nodar-DAT

b. zaza-k oškvidaps nodari Zaza.NAR he.drown.him Nodar.Nom "Zaza drowns Nodar"

The assumption is that a syntactic pattern found in (2a) is cognate with one found in (2b), specifically the argument structure pattern associated with the verb. No way of determining cognacy is explicitly stated. However, a number of 'safeguards' on the cognacy of the examples in (2) are presented:

i. the verbs, with which the case marking patterns are associated, are entirely cognate;

ii. the tense, aspect and verb class are the same in each pair,

iii. the individual verbal morphemes are cognate,

iv. the meaning is the same,

v. cases occur regularly in the context of other cases and in the context of particular verb morphology,

vi. these examples are representative of all regular verbs. (1995:349)

One question that arises is: how many of these safeguards need to be met? Many of them are clearly only relevant to cases where verbs, or verb-related patterns, are the comparanda, but other cases which meet most of the safeguards can be mentioned. In modern spoken German south of the river Main, for example, the perfect tense is used to fulfil the function performed by the simple past in other varieties of German and English (König 2005: 163). We could therefore argue that (3) was a 'correspondence set' in Harris \& Campbell's terms: 
(3) a. Er ist gekommen (Southern German) he is come

"He came"

b. He came

(English)

These correspond in the same intuitive sense as Harris \& Campbell's case pattern examples in (2), and meet safeguards (i), (iv), (v) and (vi): the meaning is the same, the verbs are cognate, and the pattern occurs systematically with all regular verbs. However, this is an example where one pattern - namely the traditional 'perfect tense' - has been extended to fulfil the role of another; there is clearly no diachronic identity between the tense forms, one of which is analytic and the other synthetic. While it is not illegitimate to compare the two constructions, it is clearly inappropriate to argue that they must constitute a correspondence set in the same sense that the term is used in phonological reconstruction.

Implicit, of course, in Harris \& Campbell's argument is that it is the argument structure patterns of the (cognate) verbs that are being compared. In the toy example in (3), there is intuitively no pattern present that can be said to be cognate. Equally, however, the safeguards on cognacy presented by Harris \& Campbell provide no basis for concluding that any two patterns are not cognate. Harris \& Campbell recognize (1995:350) that the situation here is not the same as in phonology, arguing that the conditions that enable us to ensure correspondence and cognacy need not be the same in syntax as in phonology.

One major respect in which this disparity is problematic is that the approach provides no clear basis for distinguishing structural similarity caused by language contact or parallel innovation from structural similarity caused by shared inheritance, as systematic correspondences in phonology are able to; this issue is further discussed in $\$ 5$. While I agree with Harris \& Campbell on many points, then, their rationale for stating that certain items 'correspond' to one another does not stand up to careful scrutiny: Lightfoot's correspondence problem still exists.

Barðdal \& Eythórsson (2012) and Barðdal (2013) take a similar line, assuming the framework of Construction Grammar. In their approach, constructions play a similar role to Harris \& Campbell's notion of pattern. They present a reconstruction of the dative subject construction for Proto-Germanic in this framework, arguing that two-place dative subject predicates were possible in the proto-language (2012:25-27). The example falls under the class of reconstructions that Lightfoot (2002a) would accept, since all early Germanic daughters are alike in permitting such predicates (as Barðdal \& Eythórsson demonstrate, 2012:13), and, as we have 
seen in $\$ 2.1$, Lightfoot argues that reconstruction is possible where the daughter languages show identity (2002a: 120$){ }^{6}$

The example of the dative subject construction is one where phonological cognacy of the key items involved, namely the verbs, can be independently demonstrated. It is not clear, however, that the approach would be as easy to generalize to the more complex and schematic constructions Barðdal \& Eythórsson touch upon, such as those determining constituent order at the clausal level; at the very least it would be a more difficult prospect.

Like that of Harris \& Campbell, then, the approach of Barðdal \& Eythórsson (2012) gets us some way towards evading the correspondence problem in particular cases, but the problem itself remains: criteria that are essential to the reliability of the comparative method in phonological reconstruction, e.g. the Double Cognacy Condition in (1), are simply not applicable to syntax. Thus, although I do not wish to deny that syntactic reconstruction can be done using pattern- and construction-based approaches, and that interesting and valuable results can be achieved, it is not the case that syntactic reconstruction can be pursued using the same method and on the same sure footing as phonological reconstruction. ${ }^{7}$ Nor is it the case, as claimed by Barðdal \& Eythórsson (2012:46), that a notion of construction (or pattern) is essential for syntactic reconstruction to proceed at all. In $\$ 3$ I show that this claim is false by developing a reconstructive method dependent on and compatible with current Minimalist theories of syntax.

6. Although I concur with Barðdal (2013:4) that "reconstructing stability, or structures that are stable through time, is not a banality but a genuine contribution to historical linguistics", pursuing the study of individual cognate verbs in the earliest Germanic languages to discover fine-grained differences, and attempting to reconstruct where differences do exist, would be an interesting endeavour and less open to the charge of banality. Barðdal \& Eythórsson discuss this only tentatively $(2012: 11, \mathrm{fn} 2)$.

7. An anonymous reviewer suggests that, while the approach in the current paper is to draw an analogy between syntactic and phonological reconstruction, the approach of Barðdal \& Eythórsson (2012) is based on a perceived parallel between syntactic and morphological reconstruction. However, although a few examples of 'pure' morphological reconstruction can be found in the literature (Hoenigswald 1960:70-71, Fox 1995:97-101, Koch 1996), it has long been recognized that most successful morphological reconstruction has simply been parasitic on the methods of phonological reconstruction (Fox 1995: 53; Harrison 2003:229). For this reason I find the parallel with the tried-and-tested methods of phonological reconstruction to be more promising. 


\section{Alleviating the correspondence problem in syntax: A Minimalist perspective}

As should be clear from the preceding, the correspondence problem is not a pseudo-problem, as implied by Campbell \& Harris (2002) and Barðdal \& Eythórsson (2012). In \$2 I have shown, by examining the isomorphism between phonological and syntactic variation, that the same criteria cannot be used to establish correspondence in syntax and phonology. In this section I further examine the isomorphism and establish a reconstructive method compatible with current Minimalist theories of syntax.

A crucial component of the comparative method in phonology is the notion of context, as shown in $\$ 2.3$ : sounds develop regularly according to their phonological environment. This is the Neogrammarian regularity hypothesis (Osthoff \& Brugmann 1878). How can this be captured in syntactic reconstruction?

Let us first consider the nature of phonological inventories. Phonological theories represent variation across items in phonological inventories as variation in feature matrices; the feature specification for English / $t$ /, for example, might be as in (4).

(4) $/ \mathrm{t} /=+$ coronal

$$
\begin{aligned}
& \text {-voice } \\
& \text {-cont } \\
& \text { +ant } \\
& \text { +dist }
\end{aligned}
$$

A parallel can here be drawn between phonological variation and syntactic variation within Minimalist theories of syntax. The latter have tended to adopt an approach to variation referred to as the Borer-Chomsky Conjecture (after Borer 1984, Chomsky 1995):

(5) Borer-Chomsky Conjecture: "All parameters of variation are attributable to the features of particular items (e.g., the functional heads) in the lexicon" (Baker 2008: 353).

A possible specification for the tense head $\mathrm{T}$ in English is given in (6) (after Adger \& Smith 2005), where $u$ indicates that the feature is uninterpretable in the sense of Chomsky $(1995,2000)$.

(6) $\mathrm{T}=$ tense:past

$u$ Case:nom

$u$ Num:

$u$ Pers: 
This approach enables units of syntactic variation, lexical items, to be seen as analogous to the units of phonological variation. Most usefully for the purposes of comparative reconstruction, both types of (lower-level) unit occur in context, as part of a higher-level structure containing more such units: a word or morph in the case of phonological items, and a sentence in the case of lexical items. The isomorphism between phonological and syntactic reconstruction is thus almost complete: whereas in phonology we might reconstruct the lower level unit, sounds, through their context of appearance in lexical items attested in the daughter languages, in syntax we might reconstruct the lower level unit, lexical items, through their context of appearance in sentences attested in the daughter languages.

The logic of this approach to syntactic reconstruction as laid out so far follows from the architecture of the system within Minimalism, since it employs an 'item-based' view of syntactic variation in which syntactic primitives are stored in an inventory (the lexicon). As such it illustrates that derivational models of syntax can approach the question of proto-syntax in much the same way as representational models. However, the logic of the approach is valid not only for Minimalist theories of syntax but in any approach that assumes such an 'item-based' view of syntactic variation. Construction Grammar, with its Constructicon, is one such approach (cf. Michaelis 2012 and Barðdal \& Eythórsson 2012), as is the implicit pattern-based theory of syntactic variation assumed by Harris \& Campbell (1995) and Harris (2008). It is less obvious how to extend this logic to a model which assumes variation to be encoded in the form of phrase-structure rules (as in early transformational approaches and LFG) or as the values of a fixed universal set of parameters (as in early Principles \& Parameters theories of syntax).

There is also a partial parallel in the regularity of syntactic change. Although unconditioned changes in the featural composition of phonemes may occur, many changes are represented in terms of conditioning environments, as in (7), a change that happened in some varieties of English around 1300, cf. Lass (1997:284-285):

(7) $\mathrm{r}>\varnothing / \mathrm{V}$ $[\mathrm{C},+$ coronal $]$ \#

This change yields, for instance, hash and mash from harsh and marsh. Do environmentally-conditioned syntactic changes, analogous to phonemic splits and mergers, occur? There is evidence that they do. Longobardi (2001) provides an example from the history of French, where the Latin noun casa $(m)$ "hut, house" developed into both Old French chiese, a noun that was later lost, and chies, which became the Modern French preposition chez (2001:276). Longobardi demonstrates that a 'construct state' construction is present in certain Romance languages, in which common nouns move leftward to a $\mathrm{D}$ (eterminer) position under certain conditions and that French chez shared enough of the properties of this construction to be plausibly derived from it. The phonological alternation is then explained on 
the grounds of differing stress patterns (2001:293). Importantly for our purposes, the single lexical item casa $(m)$ develops in two different ways in different contexts: where it moves to $\mathrm{D}$, it becomes the preposition chez (presumably through string reanalysis of a $\mathrm{D}$ head as a $\mathrm{P}$ head at some point during the history of French), and elsewhere it remains syntactically the same. This type of change, where the 'new' and 'old' items coexist in the same grammar, is referred to as 'layering' in work on grammaticalization (e.g. Hopper \& Traugott 2003:124), and is analogous to a phonemic split; another similar example is given in $\$ 4$, and many more can be found in the literature.

We can thus see that an effect akin to the Neogrammarian regularity hypothesis is at work. Syntactic change of a given lexical item may occur within a correctly defined context and will normally be exceptionless. This in fact follows from the nature of syntactic change. If a speaker reanalyses an item in a certain context, e.g. a noun as a preposition, there is no reason for that speaker to also postulate the original ('correct') analysis of that item in that context.

It could be objected that this regularity is not the same as Neogrammarian regularity, as it does not (necessarily) apply to classes of words, unlike regular sound change. But syntactic regularity as defined here is how the notion of regularity cashes out under the analogy we have been pursuing, in which functional lexical items are analogous to sounds: change in the lower level unit - sounds in the case of Neogrammarian regularity, lexical items in the case of syntactic regularity - occurs exceptionlessly in all relevant higher level units (words in the case of Neogrammarian regularity, sentences in the case of syntactic regularity). More generally, within the analogy given above, it is difficult to imagine that irregular syntactic change could even exist. Irregular phonological changes are those which affect only specific individual words in which the sounds occur, with no phonologically-definable context. An irregular syntactic change would affect only specific individual sentences in which the functional lexical items occur, with no syntactically-definable context. Such 'sentential diffusion' is, however, ruled out by the simple fact that sentences are normally not transmitted from generation to generation, as discussed by Lightfoot (2002a) and in $\$ 2.3$.

Pires \& Thomason (2008) challenge the idea that there can be regularity in syntactic change, arguing that the analogical spread of animacy through Slavic noun declension paradigms is not regular in the sense of regular sound change, although they admit that "the analogic changes that led to the current states of [Russian and Čakavian Serbo-Croatian] were regular in that they affected all nouns in the relevant class, case, and number categories" (2008:53). This appears to be a misunderstanding of the nature of regularity, since, as the above quotation shows, their example in fact provides evidence for it. 
They also cite personal communication from Longobardi (2008:52, fn17), stating that he has never argued for regularity of syntactic change, "considering, for instance, that change of syntactic features may spread regularly [sic] and incompletely through similar lexical items". Again, this is not a problem if we wish to maintain that syntactic change is regular. The sounds $[\mathrm{p}, \mathrm{t}, \mathrm{k}]$ are similar phonological items, and yet in phonological change $\mathrm{p}>\mathrm{b} / \mathrm{V} \_$_ $\mathrm{V}$ may perfectly well occur regularly without $\mathrm{t}>\mathrm{d}$ and $\mathrm{k}>\mathrm{g}$ also occurring in the same context. There is no need for 'similar' lexical items to pattern together in regular syntactic change, just as there is no need for 'similar' phonemes to pattern together in regular phonological change.

The parallels only run so far, however. Central to phonological reconstruction is the fact that both sounds and the units that contain them are transmitted from generation to generation. This allows hypothesized sets of cognate sounds and hypothesized sets of morphs containing them to provide mutually reinforcing evidence: in effect, a 'fossil record' of phonological change. As discussed in $\$ 2.3$, however, sentences are not transmitted in this way - the Double Cognacy Condition in (1) does not hold of syntax - and so this fossil record is absent, and the isomorphism is incomplete.

How, then, can we identify the syntactic changes that have taken place? Evidence must instead be adduced from distributional patterns of the lexical items in question, i.e. the syntactic environments in which they can be found in the daughter languages. As with phonology, surface formal similarity is not enough, although it is a useful criterion. Environmental alternations brought about by the regularity of syntactic change are key, where they exist; as in phonological reconstruction, these help to differentiate between similarity caused by genetic relationship and similarity due to other causes. Where overt phonetic material is present, as in the $\operatorname{cas} a(\mathrm{~m}) / \mathrm{chez}$ example, this may itself provide clues as to cognacy. A third heuristic, as in phonological reconstruction, is semantic similarity. Furthermore, although sometimes the generativity of syntax will obscure such patterns, 'lexical splits' analogous to phonemic splits in phonology can often still be recognized: in addition to Longobardi's example of $c h e z$, another well-known case is the Old Norse middle ending $-s k$.

\section{Identifying correspondences in syntax: The Old Norse middle voice ending}

In Old East and West Nordic texts a 'middle voice' verbal ending can be found (Barnes 2004: 146; Faarlund 2004: 123-127; Ottósson 1992, Ottoson 2008, 2009). In Old West Nordic it primarily functions as a reflexive, reciprocal or anticausative 
marker, depending on the verb to which it is attached (Ottósson 1992:66-68). Although a passive function can frequently be found in Old Swedish and Old Danish, Ottosson (2009:32) notes that the passive function is extremely rare in Old West Nordic texts. In Old East Nordic the ending surfaces as $-s$; in Old West Nordic it mainly surfaces as $-s k$, although $-m k$ is found in the first person and $-z k$ in the second person plural (Eythórsson 1995:234).

(7) Úlfrinn gapði ákafliga ok fekksk um mjök wolf.DEF gaped greatly and got.REFL about much

"The wolf gaped terribly and thrashed around"

(Prose Edda, 34)

There is debate about whether the ending should be analysed as a clitic (Faarlund 2004, Eythórsson 1995) or an affix (Ottosson 2008). The motivation for the clitic analysis is that, in terms of the hierarchy of functional projections adopted within Minimalist syntactic theories, $-s k$ is best viewed as an exponent of a head of VoiceP along the lines of similar endings in languages like Lithuanian (Eythórsson 1995: 238). However, VoiceP is thought to be below TP, and yet -sk invariably occurs outside tense and subject agreement morphemes:

(8) kalla-ð-i-sk call-PAST-3SG-VOICE

"s/he was called" (Eythórsson 1995:241)

If suffixal, this ending would violate the Mirror Principle (Baker 1985), according to which morphological derivations directly reflect syntactic derivations. This could be considered to constitute an argument for a clitic analysis. Against this, however, it can be noted that $-s k$ fails to meet at least four of the six criteria for clitichood proposed by Zwicky \& Pullum (1983:503-505): it is highly selective in that it can only follow verbs; it triggers stem allomorphy as exemplified by the contrast between kalla "I call" and kollumk "I am called/I call myself"; it may lead to lexical semantic idiosyncrasies, e.g. anda "to breathe" vs. andask "to die" (Ottósson 1992: 68); and it is treated as a unit with the verb with respect to syntactic operations. I therefore analyse $-s k$ as a suffix, but with the worrying proviso that it violates the Mirror Principle. ${ }^{8}$

8. In a strictly lexicalist view of morphology such as that of Chomsky (1995), where words enter syntactic derivations fully inflected, this is unproblematic; the trees in this section are drawn from this perspective. Assuming a theory in which words may be formed through headmovement by left-adjunction of the moved head to the higher head, on the other hand, a postsyntactic operation such as Lowering (Embick \& Noyer 2001:561-562) would be required to account for this data. 
This ending has no obvious parallels in the early Germanic languages outside Scandinavia. Gothic has mediopassive verb forms ending for the most part in -da/-dau, but these cannot be considered cognate with the North Germanic forms, since none of the phonological material is cognate. Furthermore, the Gothic forms only occur in the present indicative and subjunctive, with periphrastic constructions elsewhere (Wright 1910:191), while the Old Norse forms in -sk are also found in the past tense. Any relationship between these endings can thus be ruled out.

However, a third person reflexive pronoun with a phonologically similar shape is attested in some of the other early Germanic languages, e.g. Gothic sik, mik, Old High German sih, mih (Wright 1910:123).

(9) Jah gawandida sik Iēsus in mahtái ahmins in Galeilaian and turned REFL Jesus in power.DAT spirit.GEN to Galilee.ACC "Jesus returned in the power of the Spirit to Galilee" (Gothic Bible, Luke 4:14)

On the basis of both phonological and semantic criteria, as well as distribution, it can be argued that the Old Norse -sk ending is cognate with this pronoun. The alternation between -sk and $-m k$, in particular, is indicative of this. Old Norse itself retains the full pronoun alongside the middle ending:

(10) Grettir lá kyrr ok hroerði sik hvergi Grettir lay quiet and moved REFL nowhere "Grettir lay quietly and did not move an inch" (Grettis Saga, 35)

Considerations of directionality lead us to posit lexical split, with the independent pronoun being the original form. ${ }^{9}$ The alternative would be to posit that an ending cognate to the Old West Nordic -sk and Old East Nordic $-s$ endings existed in Proto-Germanic, which would require their independent loss in both East and West Germanic.

Formally, the change can be characterized as a pronoun first Merged as the complement of the verb, as in (11), being reanalysed as an affix whose semantic content originates in the head of VoiceP, through which the verb moves, as in (12). VoiceP corresponds to the $v \mathrm{P}$ of Chomsky (1995) and subsequent literature. Solid arrows indicate movement of the verb, and dotted lines indicate movement of the subject. Forms are given in Old Norse for simplicity's sake; the actual reanalysis must have taken place in Proto-Scandinavian.

9. Cennamo, Eythórsson \& Barðdal (2011) discuss a seemingly similar case: the development of Latin -se. The two developments seem to have taken place independently, as they argue; if true, this supports the hypothesis that in terms of directionality a reflexive pronoun is a common source for reciprocal/reflexive/anticausative endings. 
$(11)$

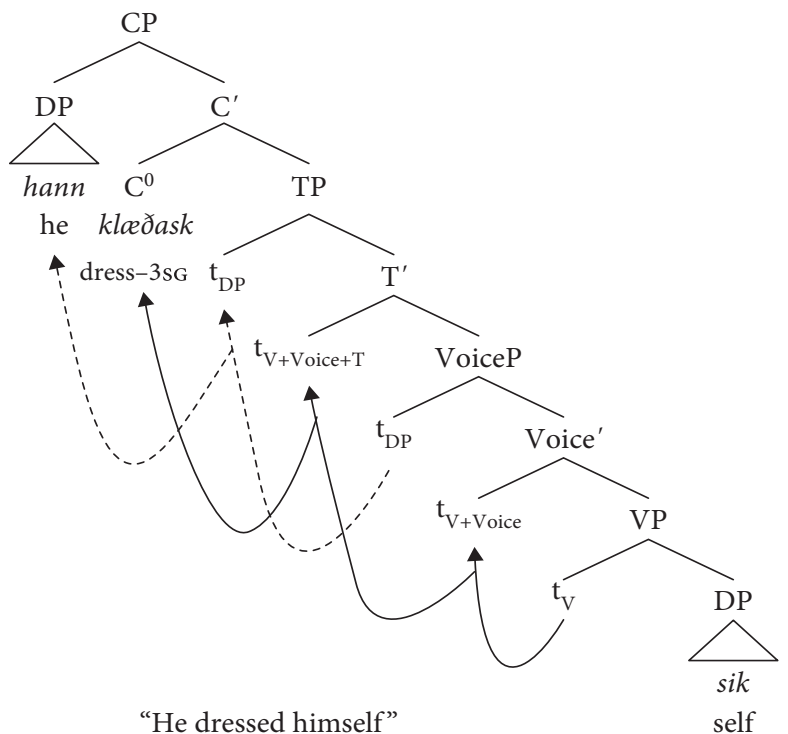

(12)

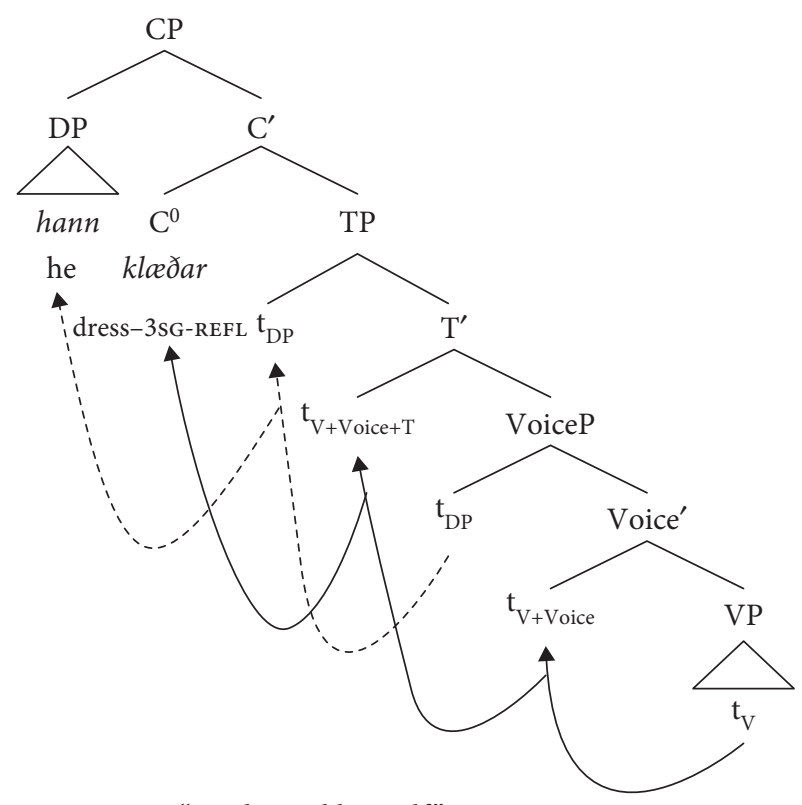

"He dressed himself"

The environment for the reanalysis is simply string-adjacency; in all other positions, such an analysis is impossible and so the pronoun is retained. A lexical split thus results; we might speculate that acquirers were unable to make the connection 
between the pronoun and the affix due to phonological differences between the forms in the two different positions, since in immediately postverbal position the pronoun is likely to have been unstressed.

In example (10) the pronoun is directly postverbal, which would, of course, still be possible in a grammar that had retained both the pronoun and the new affix. Aside from orthographic differences (presence vs. absence of $<\mathrm{i}>$ ), differences in interpretation rule out the possibility that $-s k,-z k$ and $-m k$ are simply enclitic pronouns: peir hittusk "they met" is possible with a reciprocal reading, whereas * peir hittu sik is never found, with hverr annan "each other" being the only possibility if the -sk ending is not used (Ottósson 1992: 68).

This simple example of reconstruction, concerning the origin of the Old Norse middle paradigm, has been accepted for over a hundred years (e.g. by Nygaard 1906, Gordon 1927, Faarlund 2004, Ottosson 2008). By its very straightforwardness it weighs against Lightfoot's (2002a: 120) contention that reconstruction of syntax is possible only in cases of identity among daughter languages, since in this example two different lexical items with differing functions - anticausative and reciprocal in the case of the suffix rather than purely reflexive as in the case of the pronoun - descend from a single source. As a result, we are able to reconstruct despite a morphosyntactic difference between Old Norse on the one hand and the other early Germanic languages on the other.

\section{Outlook}

$\$ 3$ and $\$ 4$ have developed and illustrated a method for the reconstruction of syntax. Although the discussion is framed in terms of the Borer-Chomsky Conjecture, the logic of the approach is not restricted to Minimalist theories but is applicable to any theory which takes an 'item-based' view of syntactic variation: for example, it is highly compatible with reconstruction using patterns as pursued by Harris (2008) or within Construction Grammar as pursued by Barðdal \& Eythórsson (2012) and Barðdal (2013). I do not claim that this method is superior to others, though it is perhaps more explicit about where and how parallels between phonological and syntactic reconstruction hold and where they do not. Nor do I claim that the method constitutes an argument in favour of my own syntactic framework, though it does cast serious doubt on the claim by Barðdal \& Eythórsson (2012:46) that Construction Grammar is the only framework in which the reconstruction of syntax is possible. In that sense my aim is modest: to dispel confusion, and to identify and resolve disagreements, rather than to present a radically new theory of syntactic reconstruction. 
The correspondence problem is real, and so difficulties remain for syntactic reconstruction within this approach as in all others. It is not at all obvious how to identify correspondences in instances of word order change, for instance. In addition, one problem for this approach is presented by contact, particularly transfer between the languages under comparison. Lexical borrowing can be ruled out in the study of phonological change by the fact that borrowed items typically fail to fit the system of regular sound correspondences established for the recipient language. However, direct phonological transfer can also occur: Dravidian influence may have caused Indic to develop retroflex consonants (Emeneau 1956: 7; Thomason \& Kaufman 1988: 141-144; though cf. Hock 1996), and it may have been as a result of influence from other Caucasian languages that Eastern Armenian developed ejectives (Vogt 1988:458; Chirikba 2008: 45). The comparative method is not able to identify such transfer in all circumstances. But under the analogy we have been pursuing, one equivalent of phonological transfer in syntactic reconstruction might be the transfer of functional lexical items, and so our syntactic comparative method is not necessarily able to identify this. Independent methods do exist for identifying such syntactic transfer: Bowern (2008:208-210) and Erschler (2009:417-419) discuss some. For example, 'exotic' constructions that are counterexamples to strong typological principles or exceptional within the language or language family itself may be identified as cases of transfer if a source can be found (Bowern 2008: 209, Erschler 2009:418). These criteria can aid in identifying syntactic transfer up to a point; however, they (and we) are not infallible. Like phonological transfer in traditional reconstruction, lexical transfer is an unavoidable confounding factor in a syntactic application of the comparative method and may obscure the history of the languages involved, leading us to incorrectly reconstruct retention of a feature rather than innovation. If the problem is greater than in phonological reconstruction, then it is only quantitatively and not qualitatively so.

The method sketched here also meets the criterion, proposed by Barðdal \& Eythórsson (2012:12), that reconstruction must be based on form and function. Functional lexical items are form-meaning pairs, just as constructions are within Construction Grammar: within Minimalism purely formal, theory-internal heads such as AgrS and AgrO are no longer accepted (cf. Chomsky 1995: ch. 4), each head being required to make a contribution to interpretation. Furthermore, varying features on functional heads are also required to trigger an interpretive effect following the so-called Fox-Reinhart intuition on optionality (Reinhart 1995, Fox 2000).

Although the correspondence problem is a genuine problem for syntactic reconstruction, I have argued that it should not cause us to give up hope of being able to reconstruct syntax at all. The partial parallels between syntactic and phonological variation provide an architecture for identifying and stating correspondences in syntax. 


\section{Conclusion}

In $\$ 2$ I discussed previous methods of syntactic reconstruction in the literature, concluding that all were problematic in some respect, and outlined the problems for reconstruction most clearly articulated by Lightfoot (2002a). By drawing a careful parallel between phonological and syntactic variation, I was able to show that at least one of these problems - the directionality problem - was no more of a difficulty to syntactic reconstruction than to its phonological counterpart. Moreover, it is possible to model the changes from a proto-syntax to the syntax of the daughter languages using a Minimalist theory of syntax. Due to the nontransmission of sentences as stored units from generation to generation, a correspondence problem exists for syntax that does not exist for phonology; I cannot therefore agree with Watkins (1964:1035) that "the 'tractability' of the syntactic system for historical investigations is only in degree different from that of the phonological". Qualitative differences between the two systems do exist. However, the nature of syntactic change is such that hypotheses about correspondences in syntax can still be advanced, as I argued in $\$ 3$ : correspondences can be suggested on the basis of distributional factors as well as formal and semantic similarity. A simple, oft-made claim about the origin of the Old Norse middle ending as a reflexive pronoun was used to illustrate this in $\$ 4$ : although uncontroversial, it is nevertheless an example of syntactic reconstruction in which the patterns found in the daughter languages are not identical.

The question of whether syntactic reconstruction is possible, then, may not be the right one to ask. Instead we should be asking how plausible individual reconstructions are. As emphasized by Lightfoot (2002b:625), the proof of the pudding is in the eating. Due to the paucity of our knowledge regarding directionality of syntactic change in many cases, and the difficulty of establishing what counts as a genuine correspondence, especially where cognacy cannot be established on the basis of phonological material, all syntactic reconstructions must remain extremely tentative. But the mere possibility of outlining such hypotheses on the basis of data and in a principled manner suggests that the enterprise of syntactic reconstruction should not be rejected out of hand.

\section{Primary sources}

'Gothic Bible': Gothic Bible, extracts in Wright (1910).

'Grettis Saga': Grettis Saga, available at http://www.utexas.edu/cola/centers/lrc/ietexts/nor/nor3-X.html.

'Prose Edda': Prose Edda, available at http://www.heimskringla.no/wiki/Gylfaginning. 


\section{References}

Adger, David \& Jennifer Smith. 2005. "Variation and the Minimalist Program". Syntax and Variation: Reconciling the biological and the social ed. by Leonie Cornips \& Karen Corrigan, 148-175. Amsterdam: John Benjamins.

Baker, Mark. 1985. "The Mirror Principle and Morphosyntactic Explanation”. Linguistic Inquiry $16.373-415$.

Baker, Mark. 2008. "The Macroparameter in a Microparametric World". The Limits of Syntactic Variation ed. by Theresa Biberauer, 351-373. Amsterdam: John Benjamins.

Barnes, Michael. 2004. A New Introduction to Old Norse, Part I Grammar. 2nd ed. Exeter, UK: Short Run Press.

Barðdal, Jóhanna. 2013. "Construction-Based Historical-Comparative Reconstruction". The Oxford Handbook of Construction Grammar ed. by Graeme Trousdale \& Thomas Hoffmann. Oxford: Oxford University Press. http://org.uib.no/iecastp/barddal/ConstructionBased\%20Historical-Comparative\%20Reconstruction.pdf

Barðdal, Jóhanna \& Thórhallur Eythórsson. 2012. "Reconstructing Syntax: Construction Grammar and the Comparative Method". Sign-Based Construction Grammar ed. by Hans C. Boas \& Ivan Sag, 257-308. Stanford: CSLI Publications. http://org.uib.no/iecastp/ ReconstructingSyntax-CSLI-Revised.pdf

Beekes, Robert S. P. 1995. Comparative Indo-European Linguistics: An introduction. Amsterdam: John Benjamins.

Borer, Hagit. 1984. Parametric Syntax. Dordrecht: Foris.

Bowern, Claire. 2008. "Syntactic Change and Syntactic Borrowing in Generative Grammar". Principles of Syntactic Reconstruction ed. by Gisella Ferraresi \& Maria Goldbach, 187-216. Amsterdam: John Benjamins.

Brugmann, Karl. 1904. Kurze vergleichende Grammatik der indogermanischen Sprachen. Strasbourg: Karl J. Trübner.

Campbell, Lyle. 1990. "Syntactic Reconstruction and Finno-Ugric". Historical Linguistics 1987: Proceedings from the 8th International Conference on Historical Linguistics ed. by Henning Andersen \& Konrad Körner, 51-94. Amsterdam: John Benjamins.

Campbell, Lyle. 2001. “What's Wrong with Grammaticalization?”. Language Sciences 23.113-161.

Campbell, Lyle \& Alice C. Harris. 2002. "Syntactic Reconstruction and Demythologizing 'Myths and the Prehistory of Grammars'". Journal of Linguistics 38.599-618.

Campbell, Lyle \& Marianne Mithun. 1980. "Syntactic Reconstruction: Priorities and pitfalls". Folia Linguistica Historica 1.19-40.

Cennamo, Michela, Thórhallur Eythórsson \& Johanna Barðdal. 2011. "The Rise and Fall of Anticausative Constructions in Indo-European: The context of Latin and Germanic" Ms., Universities of Naples/Iceland/Bergen. http://org.uib.no/iecastp/barddal/Anticausatives Cennamo-Eythorsson_Barddal.pdf

Chirikba, Viacheslav A. 2008. "The Problem of the Caucasian Sprachbund". From Linguistic Areas to Areal Linguistics ed. by Pieter Muysken, 25-93. Amsterdam: John Benjamins.

Chomsky, Noam. 1995. The Minimalist Program. Cambridge, Mass.: MIT Press.

Chomsky, Noam. 2000. "Minimalist Inquiries: The framework". Step by Step: Essays on minimalist syntax in honor of Howard Lasnik ed. by Roger Martin, David Michaels \& Juan Uriagereka, 89-156. Cambridge, Mass. MIT Press.

Clackson, James. 2007. Indo-European Linguistics. Cambridge: Cambridge University Press. 
Delbrück, Berthold. 1893-1900. Vergleichende Syntax der indogermanischen Sprachen. 3 vols. Strasbourg: Karl J. Trübner.

Dressler, Wolfgang. 1971. "Über die Rekonstruktion der indogermanischen Syntax”. Zeitschrift für vergleichende Sprachforschung 85.5-22.

Dunn, Michael, Stephen C. Levinson, Eva Lindström, Ger Reesink \& Angela Terrill. 2008. "Structural Phylogeny in Historical Linguistics: Methodological explorations applied in Island Melanesia". Language 84.710-759.

Dryer, Matthew. 1992. “The Greenbergian Word Order Correlations”. Language 68.81-138.

Embick David, \& Rolf Noyer. 2001. "Movement Operations after Syntax". Linguistic Inquiry 32.555-595.

Emeneau, Murray B. 1956. "India as a Linguistic Area”. Language 32.3-16.

Erschler, David. 2009. "Possession Marking in Ossetic: Arguing for Caucasian influence". Linguistic Typology 13.417-450.

Eythórsson, Thórhallur. 1995. Verbal Syntax in the Early Germanic Languages. Ph.D. dissertation, Cornell University.

Faarlund, Jan Terje. 2004. The Syntax of Old Norse. Oxford: Oxford University Press.

Ferraresi, Gisella \& Maria Goldbach, eds. 2008. Principles of Syntactic Reconstruction. Amsterdam: John Benjamins.

Fox, Anthony. 1995. Linguistic Reconstruction: An introduction to theory and method. Oxford: Oxford University Press.

Fox, Danny. 2000. Economy and Semantic Interpretation. Cambridge, Mass.: MIT Press.

Friedrich, Paul. 1975. Proto-Indo-European Syntax: The order of meaningful elements. (= Journal of Indo-European Studies Monograph, 1). Butte, Mont. Journal of Indo-European Studies.

Greenberg, Joseph. 1963. "Some Universals of Grammar with Particular Reference to the Order of Meaningful Elements". Universals of Grammar ed. by Joseph Greenberg, 73-113. Cambridge, Mass.: MIT Press.

Gordon, Eric V. 1927. An Introduction to Old Norse. Oxford: Clarendon.

Hale, Mark. 2007. Historical Linguistics: Theory and method. Oxford: Blackwell.

Harris, Alice C. 1985. Diachronic Syntax: The Kartvelian case. New York: Academic Press.

Harris, Alice C. 2008. "Reconstruction in Syntax: Reconstruction of patterns". Principles of Syntactic Reconstruction ed. by Gisella Ferraresi \& Maria Goldbach, 73-95. Amsterdam: John Benjamins.

Harris, Alice C. \& Lyle Campbell. 1995. Historical Syntax in Cross-Linguistic Perspective. Cambridge: Cambridge University Press.

Harrison, S. P. 2003. "On the Limits of the Comparative Method". The Handbook of Historical Linguistics ed. by Brian D. Joseph \& Richard D. Janda, 213-243. Oxford: Blackwell.

Hawkins, John A. 1990. “A Parsing Theory of Word Order Universals”. Linguistic Inquiry 21.223261.

Hock, Hans Heinrich. 1996. "Subversion or Convergence? The issue of pre-vedic retroflexion reconsidered". Studies in the Linguistic Sciences 23.73-115.

Hockett, Charles F. 1960. “The Origin of Speech”. Scientific American 203.89-97.

Hoenigswald, Henry M. 1960. Language Change and Linguistic Reconstruction. Chicago: University of Chicago Press.

Hopper, Paul \& Elizabeth Closs Traugott. 2003. Grammaticalization. 2nd ed. Cambridge: Cambridge University Press.

Hurford, James R. 2011. The Origins of Grammar: Language in the light of evolution. Oxford: Oxford University Press. 
Jackendoff, Ray. 1994. Patterns in the Mind: Language and human nature. New York: Basic Books.

Jeffers, Robert J. 1976. "Syntactic Change and Syntactic Reconstruction". Current Progress in Historical Linguistics: Proceedings of the Second International Conference on Historical Linguistics ed. by W. M. Christie, Jr., 1-15. Amsterdam: North-Holland.

Juge, Matthew L. 2002. "Unidirectionality in Grammaticalization and Lexical Shift: The case of English rather". Proceedings of the Twenty-Eighth Annual Meeting of the Berkeley Linguistics Society ed. by Julie Larsen \& Mary Paster, 147-154. Berkeley: Berkeley Linguistics Society.

Keenan, Edward L. 2003. "An Historical Explanation of Some Binding-Theoretic Facts in English". The Nature of Explanation in Linguistics ed. by John Moore \& Maria Polinsky, 153-189. Stanford: CSLI Publications.

Kiparsky, Paul. 1988. "Phonological Change". Linguistics: The Cambridge survey, Vol. 1 ed. by Frederick J. Newmeyer, 363-415. Cambridge: Cambridge University Press.

Koch, Harold. 1996. "Reconstruction in Morphology". The Comparative Method Reviewed: Regularity and irregularity in language change ed. by Mark Durie \& Malcolm Ross, 218 263. Oxford: Oxford University Press.

König, Werner H. 2005. dtv-Atlas Deutsche Sprache. 15th ed. Munich: Deutscher Taschenbuch Verlag.

Lass, Roger. 1993. "How Real(ist) are Reconstructions?". Historical Linguistics: Problems and perspective ed. by Charles Jones, 156-189. London: Longman.

Lass, Roger. 1997. Historical Linguistics and Language Change. Cambridge: Cambridge University Press.

Lehmann, Winfred P. 1974. Proto-Indo-European Syntax. Austin: University of Texas Press.

Lightfoot, David W. 1979a. Principles of Diachronic Syntax. Cambridge: Cambridge University Press.

Lightfoot, David W. 1979b. Review of Mechanisms of Syntactic Change ed. by Charles N. Li (Austin: University of Texas Press, 1977). Language 55.381-395.

Lightfoot, David W. 2002a. "Myths and the Prehistory of Grammars". Journal of Linguistics 38.113-136.

Lightfoot, David W. 2002b. "More Myths". Journal of Linguistics 38.619-626.

Lightfoot, David W. 2006. How New Languages Emerge. Cambridge: Cambridge University Press.

Longobardi, Giuseppe. 2001. "Formal Syntax, Diachronic Minimalism and Etymology: The history of French chez". Linguistic Inquiry 32.275-302.

Longobardi, Giuseppe \& Cristina Guardiano. 2009. “Evidence for Syntax as a Signal of Historical Relatedness". Lingua 119.1679-1706.

McMahon, April M. S. 1994. Understanding Language Change. Cambridge: Cambridge University Press.

von Mengden, Ferdinand. 2008. "Reconstructing Complex Structures: A typological perspective". Principles of Syntactic Reconstruction ed. by Gisella Ferraresi \& Maria Goldbach, $97-$ 119. Amsterdam: John Benjamins.

Michaelis, Laura A. 2012. "Making the Case for Construction Grammar". Sign-Based Construction Grammar ed. by Hans C. Boas \& Ivan Sag, 31-68. Stanford: CSLI Publications. http://spot. colorado.edu/ michaeli/Making_the_case.pdf.

Miller, D. Gary. 1975. "Proto-Indo-European: VSO, SOV, SVO or all three?”. Lingua 37.31-52.

Nichols, Johanna. 2003. "Diversity and Stability in Language". The Handbook of Historical Linguistics ed. by Brian D. Joseph \& Richard D. Janda, 283-310. Oxford: Blackwell.

Nygaard, Marius. 1906. Norrøn Syntax. Kristiania: Aschehoug. 
Osthoff, Hermann \& Karl Brugmann. 1878. Morphologische Untersuchungen auf dem Gebiet der indogermanischen Sprachen, Vol. 1. Leipzig: Hirzel.

Ottósson, Kjartan. 1992. The Icelandic Middle Voice: The morphological and phonological development. Ph.D. dissertation, Lund University.

Ottosson, Kjartan. 2008. "The Old Nordic Middle Voice in the Pre-Literary Period". Interdependence of Diachronic and Synchronic Analyses ed. by Folke Josephson \& Ingmar Söhrman, 185-219. Amsterdam: John Benjamins.

Ottosson, Kjartan. 2009. "The Anticausative and Related Categories in the Old Germanic Languages". Ms., University of Oslo.

Pires, Acrisio, \& Sarah G. Thomason. 2008. "How Much Syntactic Reconstruction is Possible?". Principles of Syntactic Reconstruction ed. by Gisella Ferraresi \& Maria Goldbach, 27-72. Amsterdam: John Benjamins.

Reinhart, Tanya. 1995. "Interface Strategies". OTS Working Papers in Linguistics, University of Utrecht.

Ringe, Don, Tandy Warnow \& Ann Taylor. 2003. "Indo-European and Computational Cladistics". Transactions of the Philological Society 100.59-129.

Roberts, Ian. 2007. Diachronic Syntax. Oxford: Oxford University Press.

Schleicher, August. 1853. "Die ersten Spaltungen des indogermanischen Urvolkes". Allgemeine Monatsschrift für Wissenschaft und Literatur 1853.786-787.

Smith, Neil V. 1981. "Consistency, Markedness and Language Change: On the notion 'consistent language'”. Journal of Linguistics 17.39-54.

Steels, Luc, \& Joachim de Beule. 2006. "Unify and Merge in Fluid Construction Grammar". Symbol Grounding and Beyond ed. by Paul Vogt, Yuuya Sugita, Elio Tuci \& Chrystopher Nehaniv, 197-223. Berlin: Springer.

Thomason, Sarah G. \& Terrence Kaufman. 1988. Language Contact, Creolization, and Genetic Linguistics. Berkeley \& Los Angeles: University of California Press.

Trask, Robert L. 1996. A Dictionary of Phonetics and Phonology. London \& New York: Routledge.

Vogt, Hans. 1988. Linguistique caucasienne et arménienne. Oslo: Norwegian University Press.

Walkden, George. 2009. The Comparative Method in Syntactic Reconstruction. M.Phil. dissertation, University of Cambridge. http://personalpages.manchester.ac.uk/staff/george.walkden/Walkden_2009_CompMeth.pdf.

Watkins, Calvert. 1964. "Preliminaries to the Reconstruction of Indo-European Sentence Structure". Proceedings of the Ninth International Congress of Linguists ed. by Horace G. Lunt, 1035-1045. The Hague: Mouton.

Watkins, Calvert. 1976. "Towards Proto-Indo-European Syntax: Problems and pseudo-problems". Papers from the Parasession on Diachronic Syntax ed. by Sanford Steever, Carol Walker \& Salikoko Mufwene, 306-326. Chicago: Chicago Linguistic Society.

Wichmann, Søren. 2008. "The Study of Semantic Alignment: Retrospect and the state of the art”. The Typology of Semantic Alignment ed. by Mark Donohue \& Søren Wichmann, 3-23. Oxford: Oxford University Press.

Winter, Werner. 1984. "Reconstructing Comparative Linguistics and the Reconstruction of the Syntax of Undocumented Stages in the Development of Language and Language Families". Historical Syntax ed. by Jacek Fisiak, 613-626. Berlin: Mouton de Gruyter.

Wright, Joseph. 1910. Grammar of the Gothic Language. Oxford: Clarendon.

Zwicky, Arnold M., \& Geoffrey K. Pullum. 1983. "Cliticization vs. Inflection: English n't". Language 59.502-513. 


\title{
Résumé
}

Si des pans entiers de la phonologie et de la morphologie des proto-langues ont pu être reconstruits grâce à la méthode comparative, la syntaxe est restée, elle, peu touchée. Jeffers (1976) et Lightfoot (2002a), entre autres, ont émis des doutes sur la possibilité de reconstruire véritablement toute syntaxe, avançant un problème fondamental dans l'application à la syntaxe des techniques de la reconstruction phonologique. D’autres, tels que Harris \& Campbell (1995), et, par la suite, Barðdal \& Eythórsson (2012), ont fait valoir que ce problème ne survenait pas dans leur système. Nous faisons ici un examen critique de l'isomorphisme entre les reconstructions phonologique et syntaxique, en nous appuyant sur la vision 'par item' de la variation syntaxique telle qu'elle est conçue dans le cadre des théories de la syntaxe du programme minimaliste, des grammaires de construction et de bien d'autres encore. Afin d'étayer cette démarche, nous présentons une étude de cas portant sur le suffixe -sk en vieux scandinave. Si nous n'en tirons pas une conclusion aussi pessimiste que celle de Lightfoot (2002a), nous n'en pensons pas moins que 'le problème de la correspondance' est bel et bien réel, et que, nécessairement, la reconstruction de la syntaxe est plus difficile et plus conjecturale que celle de la phonologie.

\section{Zusammenfassung}

Während die Phonologie und Morphologie von Proto-Sprachen zu einem bemerkenswert großen Teil unter Anwendung der komparativen Methode rekonstruiert worden sind, hinkt die Syntax hinterher. Nicht nur Jeffers (1976) und Lightfoot (2002a) haben Bedenken darüber geäußert, ob Syntax überhaupt rekonstruiert werden kann, da es problematisch sei, Techniken, die für die phonologische Rekonstruktion entwickelt wurden, auf die Syntax anzuwenden. Andere Forscher wie Harris \& Campbell (1995) sowie Barðdal \& Eythórsson (2012) haben behauptet, dass dieses Problem in ihrem Framework nicht auftauche. Im vorliegenden Aufsatz wird die Isomorphie zwischen phonologischer und syntaktischer Rekonstruktion einer kritischen Prüfung unterzogen. Ermöglicht wird dies durch eine 'Item-basierte' Sicht auf die syntaktische Variation, wie sie beispielsweise innerhalb minimalistischer und konstruktionsgrammatischer Syntaxtheorien und vergleichbaren Ansätzen vertreten wird. Eine Fallstudie zum Suffix -sk im frühen Nordgermanischen wird zugunsten dieser Herangehensweise angeführt. Obwohl die Schlussfolgerung nicht so pessimistisch ausfällt wie diejenige von Lightfoot (2002a), ergibt sich doch, dass das 'Korrespondenzproblem' tatsächlich existiert und dass die Rekonstruktion der Syntax daher notwendigerweise schwieriger und spekulativer ist als die der Phonologie.

\author{
Author's address \\ School of Arts, Languages \& Cultures \\ Samuel Alexander Building \\ Oxford Road \\ MANCHester M13 9PL \\ United Kingdom \\ george.walkden@manchester.ac.uk
}

